\title{
La espiga solitaria. \\ El duelo como escritura en la Oración del 9 de febrero de Alfonso Reyes
}

\author{
Víctor Barrera Enderle \\ Universidad Autónoma de Nuevo León
}

Resumen:

La violenta muerte del padre de Alfonso Reyes, el general Bernardo Reyes, representó un punto de quiebre en la vida y la obra del hijo. Tras el deceso, vino, para Alfonso Reyes, una suerte de prolongado exilio que lo hizo refugiarse en la escritura. Una buena parte de su obra contiene referencias a este trágico suceso; sin embargo, es en el ensayo "Oración del 9 de febrero" donde aborda explícitamente el tema. En este trabajo analizaré la manera en que Reyes hace de la escritura una suerte de duelo con el fin de humanizar la figura del padre, para así poder definirse como escritor y como un sujeto que ha elegido su propio destino.

Palabras clave: Ensayo mexicano, duelo, escritura, Alfonso Reyes.

\section{Abstract}

The violent death of Alfonso Reyes's father General Bernardo Reyes, represented a turning point in the life and work of the child. After the death, came, to Alfonso Reyes, a sort of prolonged exile where he 
refuged writing. A good deal of his work contains references to this tragic event; however it is in the essay "Oración del 9 de febrero" the place in which he explicitly addresses the issue. In this paper I will discuss how Reyes makes writing a sort of duel to humanize the father figure, in order to be defined as a writer and as an individual who has chosen his own destiny.

Keywords: Mexican essay, Duel, Writing, Alfonso Reyes.

... Desde entonces mi noche tiene voces, huésped mi soledad, gusto mi llanto.

Alfonso Reyes

\begin{abstract}
A lfonso Reyes comenzó su personal y peculiar Oración mar$\mathrm{A}_{\text {cando, desde el título y las primeras líneas, una fecha tácita }}$ y sumamente simbólica: el día que daba inicio a su escritura se cumplían diecisiete años de la muerte del padre. La dolorosa efeméride detonaba la redacción; sin embargo, la gestación venía de mucho antes: desde el sonido de la metralla que terminó con la vida de Bernardo Reyes el domingo 9 de febrero de 1913. La violenta muerte del general, ocurrida a las puertas del Palacio Nacional, desencadenó la llamada "Decena trágica": esos diez días que marcaron el fin de la presidencia de Francisco Madero y el inicio de la dictadura de Victoriano Huerta. Esos son los datos duros, los hechos registrados por la prensa y los historiadores. En una primera lectura, y con los antecedentes que acabo de mencionar, la atención parecería ir hacia atrás, retrocediendo en el tiempo. Pero no es así, o no lo es completamente. La Oración del 9 de febrero indaga en el universo de la subjetividad, tantea lo que hubiera podido pasar, y cuenta lo que, en cierta medida, no pasó, pero igual pasó tras ese trauma crucial en la vida de Alfonso Reyes y del México moderno.
\end{abstract}


Tras la muerte del padre, el camino se bifurcó para el hijo, quien decidió tomar el sendero de la vocación literaria y sellar su destino. Eso lo sabemos bien. Sin embargo, al comenzar a esbozar su Oración, en Buenos Aires, esa mañana de febrero de 1930, en pleno verano austral, Reyes recorrió simbólicamente el otro camino, el clausurado. Sería un ejercicio peligroso y lleno de dolor: "Es difícil bajar a la zona más temblorosa de nuestros pudores y respetos." (Reyes, 1990: 27) Ese descenso dantesco hacia sí mismo, ¿representa una forma de cierre, de trabajo de duelo, por decirlo así, o, por el contrario: es la exploración de la transformación profunda del propio "yo", un camino sin retorno posible? ¿Para quién escribe Reyes esa peculiar obra? ¿Para el público mexicano de su tiempo, para él mismo?

¿Qué le pasaba al autor regiomontano en ese momento? Era el inicio de la década del treinta, él se encontraba, como recién apunté, en Buenos Aires, cumpliendo con sus últimas funciones como embajador, antes de dejar el cargo y trasladarse a Río de Janeiro para asumir la representación mexicana en Brasil. En lo literario, podría decirse que era un "escritor consagrado", un autor que, en poco menos de veinte años de carrera, había logrado hacerse un nombre. Individualizarse a través de su propia creación. En ese lapso había recorrido, con éxito, las principales capitales de la geografía literaria hispánica: México, Madrid y Buenos Aires.

En México, no hacía mucho había tomado posesión como presidente Pascual Ortiz Rubio (por cierto, el mismo día que asumió el cargo fue objeto de un atentado por parte de un seguidor de José Vasconcelos). ${ }^{1}$ Estamos en plena consolidación del periodo conocido como el Maximato, esto es, la prolongación del poder

${ }^{1}$ En su Diario, entrada del 5 de febrero de 1930, Reyes apunta escuetamente: "Tomó posesión en México el presidente Ortiz Rubio. En la tarde, atentado contra él de que resulta herido en la mandíbula. Me llega noticia en la noche" (2010: 169). 
presidencial de Plutarco Elías Calles por medio de políticos vicarios, como el propio Ortiz Rubio. Tras dos décadas de procesos revolucionarios, el país no se había estabilizado todavía. La muerte del padre representaba, simbólicamente, un acontecimiento histórico presente, un hecho que la historiografía oficial quería dejar atrás y condenar al olvido.

Reyes precisaba, pues, cerrar el duelo (o transformarlo en otra cosa) y entrar en una fase de aceptación (o adecuación); necesitaba elaborar narrativamente la pérdida y confrontarla con su propia condición de sujeto. En sus Diarios de aquellos días casi no hay referencias al proceso de creación de la Oración, salvo una nota reveladora y un episodio entre curioso y algo perturbador. Me ocuparé primero de la nota. En la entrada del 16 de abril de 1929, Reyes da cuenta de la recepción del libro de memorias que su hermano Rodolfo acaba de publicar en España. Rodolfo fue quien acompañó (y alentó) al general en su desventurada y postrera revuelta militar. Apunta Reyes: "De repente tuve grata sorpresa [de] recibir libro de mi hermano Rodolfo, desde Madrid: De mi vida (memorias politicas) que llega hasta la muerte de mi padre y forma el tomo I. Esto harále bien moralmente por ser principio de su catarsis, e históricamente, sin duda. Como el tomo más bien está dedicado a mi padre y su política, ${ }^{2}$ déjame abierto y limpio el camino para mi Crónica de Monterrey, en que daré silueta humana a mi padre"(2010: 122). ${ }^{3}$

${ }^{2}$ Rodolfo expone que sus memorias son, en rigor, las vivencias que tuvo junto a su padre los últimos catorce años de vida del general: "Él fue, a la par que mi padre, mi maestro, mi amigo, mi jefe y no debe, por ende, resultar extraño que estos apuntes, al narrar el período en el que él vivió, sean más la historia de su participación en la vida pública que otra cosa”, así que "téngase ello humanamente en cuenta y acéptese mi obra tal como sinceramente se presenta, como las memorias políticas de un hijo amante sobre la vida de su padre y la propia suya, en cuanto afectaron a intereses nacionales" (Reyes, 1929: 9).

${ }^{3}$ La Crónica de Monterrey no vería la luz sino hasta 1960, cuando Reyes ya había muerto; su redacción definitiva se dio en el año de 1959 y es más un escrito so- 
Ahora el episodio. En marzo de ese año, es decir, a más de un mes de haber comenzado la escritura de su texto, Reyes asiste a la casa de la aristócrata argentina Nieves Gonet de Rinaldini a una sesión espiritista (entonces se decía de psicometría) con la médium italiana Irma Maggi. Lleva consigo una prenda: la gorra de cazador que el general se había calzado el día de su trágica muerte. Sin advertir el origen ni el dueño de la pieza, Reyes la coloca ante la vista de la médium. He aquí sus palabras:

Anoche, en casa de Nieves, sesión de psicometría, de la vidente Irma Maggy, citada por Richet en su Tratado de metapsíquica. Lo más notable fue mi prueba, de todos absolutamente ignorada, salvo de mi mujer a quien previne el mayor secreto. Le llevé, bajo sobre (y dentro del mismo sobre se limitó ella a palparla) la gorra cazadora con que murió mi padre. ${ }^{4} \mathrm{El}$ resultado admirable (y más si se tiene en cuenta lo absurdo que parecería ponerse a escribir de sangre y visiones épicas en medio de una reunión social y amable como aquella)[...] (2010: 175)

El mensaje que le fue "dictado" a la médium partía de las impresiones que ese objeto misterioso le provocaba al tacto (mediado, recordemos, por el sobre). Primero: una "extraña indefinida sensación", que hacía flotar algo "trágico" en el ambiente, "como si se

bre el mundo que lo envolvió en su juventud (principalmente Monterrey), que una biografía del padre. Sólo en Parentalia, escrito entre 1949 y 1957, se hace cargo de la historia del general Reyes (en la tercera parte, titulada "Enseña de Occidente"). El único texto donde sí logra su propósito de humanizar discursivamente al padre fue la Oración del 9 de febrero.

${ }^{4}$ En las ya referidas memorias de Rodolfo Reyes se describe la indumentaria que vistió el general ese funesto día: "Serían las siete de la mańana cuando mi padre, con traje negro sport, botas militares, pequeño sombrero de fieltro gris verde y abrigado con un capote de general español (obsequio de S. M. el rey de España), montó frente al cuartel anexo a Santiago un caballo de gran alzada, colorado oscuro, llamado Lucero [...]" (1929: 229). 
hubiese derramado la sangre". Después: una ristra de impresiones aleatorias: alarma, confusión, intriga, repercusión. "Te veo distinto al que eres ahora", le espeta la vidente al escritor regiomontano, y prosigue: "siento hordas de fanáticos que corren al rescate", además de "algo trágico y espectral", algo grave, remarca y finaliza con esta frase lapidaria: "veo guerreros y veo también una suerte de dinastía que cae” (2010: 212).

Estas dos referencias nos pueden sugerir muchas cosas. Me quedo con dos: primero, la intención de dotar de humanidad a la figura paterna y, segundo, la posesión de ese objeto o fetiche, la gorra del padre, que nos indica un fuerte apego emocional. No es mi intención entrar en los terrenos de la psicología, ni mucho menos aventurar ningún tipo de diagnóstico clínico, pero sí debo señalar lo entiendo aquí por duelo y la peculiar función que éste cumple en la redacción de la Oración del 9 de febrero. Sin duda, el ensayo más emblemático sobre el tema es "Duelo y melancolía", escrito por Freud en 1915 y publicado un par de años después. En un interesante juego de oposiciones y acercamientos, Freud contrasta el duelo con la melancolía. Considera al primero como un "afecto normal" (Freud, 2006: 241) y a la segunda, en su incapacidad para superar el trauma, como una "disposición enfermiza". Si bien la terminología médica ha terminado por trocar el concepto de melancolía por el de depresión, me quedaré con el primero y apelaré a su raíz etimológica: esa bilis negra, que denunciaban los griegos, y que se transformaba en una tristeza vaga, indefinida, en quienes la padecían, obsesionándolos finalmente en ciertas monomanías.

El duelo, en palabras del doctor Freud, sería "por regla general, la reacción frente a la pérdida de una persona amada o de una abstracción que haga sus veces, como la patria, la libertad, un ideal, etc."; en oposición, la melancolía "se singulariza en lo anímico por una desazón profundamente dolida, una cancelación del interés por el mundo exterior, la pérdida de la capacidad de amar, la inhi- 
bición de toda productividad y una rebaja en el sentimiento de sí [...]" (2006: 242).

La reacción provocada por el duelo (que, por cierto, presenta muchas de las características de la melancolía) sería necesariamente pasajera. Después del desequilibrio ante la pérdida, se volvería al "yo normal". El melancólico presentaría los síntomas de un ser descentrado, ajeno de sí mismo. Quien padece el duelo no pierde, o no del todo, su conexión con la realidad: "en el duelo — sostiene Freud-, el mundo se ha hecho pobre y vacío; en la melancolía, eso le ocurre al yo mismo" (2006: 243).

Sin embargo, hay en la melancolía una forma, una manera oblicua de capturar la "verdad de la vida" (¿su sin sentido?): "En el melancólico podría casi destacarse el rasgo opuesto, el de una acuciante franqueza que se complace en el desnudamiento de sí mismo" (2010: 245). Subsiste en ella el rebasamiento del objeto de la pérdida, digamos que éste se compenetra en el melancólico. El consuelo de permanecer con vida, en contraste con el objeto amado, no basta para sobrellevar la pena y regresar al ámbito de la "normalidad". Algo inquietante permanece.

$\mathrm{Y}$ ese es precisamente el punto a donde me gustaría llegar. El duelo en la escritura de Reyes no es una forma de superación, sino de asimilación: es la expresión elocuente de un melancólico. "Yo siento — dice el autor de la Oración — que, desde el día de su partida, mi padre ha empezado a entrar en mi alma y a hospedarse en ella a sus anchas. Ahora creo haber logrado ya la absorción completa y — si la palabra no fuera tan odiosa- la digestión completa" (1990: 28). El duelo "físico", por decirlo así, lo llevó de inmediato, casi desde el instante que supo la trágica noticia: "Después me fui rehaciendo como pude, como se rehacen para andar y correr esos pobres perros de la calle a los que un vehículo destroza una pata; como aprenden a trinchar con una sola mano los mancos; como aprenden los monjes a vivir sin el mundo, a comer sin sal los en- 
fermos. Y entonces, de mi mutilación saqué fuerzas. Mis hábitos de imaginación vinieron en mi auxilio" (1990: 27). A fuerza de empeño, dejó todo y comenzó de nuevo. Vivió entre la burocracia diplomática y las faenas de la escritura periodística. Pero ni la vida ni la literatura fueron ya las mismas que antes para él.

Evocar al padre implicaba también cuestionarse como hijo. ¿En qué medida era él la prolongación del padre? ¿Y en qué medida no lo era? La escritura, que es en sí una forma de ordenar el tiempo y de darle sentido al pasado, sería la vía para procesar el duelo o para hacer productiva la melancolía. Al igual que Kafka en la estremecedora "Carta al Padre", Reyes recurría a la escritura para conjurar las distancias, para tratar de abrir nuevos canales de comunicación. Pero sobre todo, ambos, el escritor checo y el autor regiomontano, tenían como destinatario final a ellos mismos. Los padres, uno muerto y el otro indiferente ante la vocación del hijo, jamás se darían por enterados.

Alfonso Reyes redactó la Oración entre febrero y agosto de ese año. Partió de la fecha de la muerte y terminó el día del cumpleaños del general. Recorrió el camino inverso: de la muerte a la vida, del olvido a la memoria. La oración como género de escritura, como obra de elocuencia y persuasión, está cercana a la plegaria: busca la conmoción de la audiencia; pero la oración alfonsina no es una alabanza al padre ni tampoco la defensa desaforada de sus acciones, o no completamente: es, sobre todo, una interpretación de la ausencia, un conjuro contra el dolor. Una lectura que confronta y complementa las diferencias entre el padre y el hijo. Hace tiempo, en un ensayo sobre la amistad literaria entre Alfonso Reyes y Pedro Henríquez Ureña, ${ }^{5}$ trabajé brevemente este aspecto. Entonces me interesaba destacar que, dentro de las amplias funciones que se crean dentro de una amistad de esa naturaleza, Henríquez

${ }^{5}$ Véase mi libro De la amistad literaria (Ensayo sobre la genealogía de una amistad: Alfonso Reyes / Pedro Henríquez Ureña, 1906-1914) (2006). 
Ureña jamás cumplió, como afirmaban algunos, el rol simbólico de padre de Alfonso Reyes. No. La figura paterna opera en la escritura alfonsina como oposición y como proyección. Bernardo Reyes es la figura de otro tiempo, o mejor, de otra temporalidad, representa un género literario superado: el romanticismo literario hispanoamericano. El hijo lo describía así: "Él vivía en Monterrey, ciudad de provincia. Yo vivía en México, la capital. Él me llevaba más de cuarenta años, y se había formado en el romanticismo tardío de nuestra América. Él era soldado y gobernante. Yo iba para literato" (1990: 25).

La Oración del 9 de febrero es un tipo de escritura que cubre, al mismo tiempo y con gran maestría, varios registros: el biográfico, por supuesto, pero también el histórico y el literario. Además de que compone una tópica personal: la geografía de la formación literaria de Alfonso Reyes. En esa cartografía letrada, un espacio concentra toda la carga simbólica: Monterrey. Reyes elaboró una poderosa condensación que terminó por fusionar al padre con el suelo nativo. El legado político y material del general fue leído como un texto escrito sobre la superficie del territorio regiomontano. Si la historia nacional reciente era dolorosa, tan dolorosa para él que lo obligaría a guardar su Oración durante el resto de sus días sobre la tierra, Monterrey, en contraste, representaba lo "definitivo", al menos esa era la lectura que el autor de Visión de Anáhuac hacía desde la doble distancia: temporal y espacial.

La dimensión histórica parte del hecho desgarrador, a saber, que el padre no supo leer su propia circunstancia, no se enteró que su tiempo y su género literario ya habían pasado. Era un romántico exiliado del romanticismo, que vivía ahora en una era donde los intereses materiales (y monetarios) se imponían sobre los viejos ideales nacionalistas. Reyes interpretó este acontecimiento como un acto de consecuencia, como una manera de hacer vida (o muerte) de las palabras: "Entonces entendí que él había vivi- 
do las palabras, que había ejercido su poesía con la vida, que era todo él como un poema en movimiento, un poema romántico de que hubiera sido a la vez autor y actor. Nunca vi otro caso de mayor frecuentación, de mayor penetración entre la poesía y la vida" (1990: 38). Con este desplazamiento, la Oración ingresa el reino de la dimensión literaria, y con ella logra una justificación de los actos. La distancia en el plano de los discursos (de cualquiera índole) y el heterogéneo ámbito de la realidad suele ser en América Latina muy grande, y quien lleva sus lecturas a lo cotidiano suele ser juzgado como un loco, como un Quijote. Reyes, en su lectura sobre el padre, cambió al político por el personaje, pero no ocultó las acciones del hombre público, sólo las colocó en una perspectiva más amplia, más allá de lo contingente o lo inmediato.

Bernardo Reyes pertenecía, desde esta mirada, a la generación que podríamos llamar como la de los liberales literarios. La elite ilustrada que, desde la mitad del siglo XIX, proyectó en la escritura la imagen de los modernos estados-nacionales que habrían de consolidar a los nuevos países hispanoamericanos, con la salvedad de que el general Reyes literalmente peleó por esa apuesta y, de hecho, la llevó a cabo en ese lugar definitivo para Reyes que era el suelo nativo: "Naturalmente, él se tenía por hombre de acción, porque aquello de sólo dedicarse a soñar se le figuraba una forma abominable del egoísmo." El padre no comprendía la distancia entre la ficción y la realidad, entre la historia y la subjetividad (jtodos los actos eran públicos!): "no veía la diferencia entre la imaginación y el acto” (1990: 38), rememoraba el vástago diecisiete años después de la tragedia.

De manera súbita, la Oración comienza a formular tácitamente una serie de preguntas: ¿qué hubiera pasado si el general Reyes hubiese triunfado en su intentona de golpe militar, si hubiera llegado a la presidencia? Es probable, y así lo sospechaba Reyes, que el desenlace no hubiera sido muy distinto del acontecimiento real, 
porque, como bien había apuntado, su tiempo histórico ya había pasado. Pero esa no es la pregunta principal, con el poder de la evocación y de la recreación literaria, Reyes iba más atrás en el tiempo y exploraba otro universo de posibilidades. ¿Qué hubiera sucedido si Bernardo Reyes hubiese llegado a la presidencia en el momento justo, en el cénit de su carrera política? Otro sería el destino del país, sugería el hijo escritor y presentaba como argumento irrefutable el legado concreto: el suelo nativo. Ahí estaban la vitalidad y el crecimiento de Monterrey, el desarrollo de todo el estado de Nuevo León. La fuerza vigorosa de la ciudad natal era la proyección a escala de lo que hubiera sucedido si los hados de la Historia se hubiesen comportado de manera diferente.

A mí me gustaría, sin embargo, aventurar otra hipótesis. La muerte del padre, tal como aconteció, fue uno de los factores determinantes en la concreción del Reyes escritor. Y, por supuesto, no soy el único en sostener esto. En un artículo, publicado en el periódico Excélsior el 7 de febrero de 1968, el periodista neolonés José Alvarado se cuestionó por el mismo destino heteróclito y alternativo. Pongamos por caso que Bernardo Reyes hubiera tenido éxito en su empresa guerrera; una vez adentrados en el terreno especulativo, el periodista se pregunta: “¿Cuál hubiese sido el destino de algunos hombres si Bernardo Reyes, en vez de caer muerto, consigue apoderarse del palacio nacional y llega a convertirse en el caudillo de la insurrección victoriosa y el amo de México?” (1985: 52)

La primera respuesta es demoledora: se hubiera convertido, a la postre, en un traidor a la patria, y habría caído sobre él el funesto destino que finalmente le correspondió a Huerta, pues habría tenido que asesinar al presidente Madero y al vicepresidente Pino 
Suárez. ${ }^{6}$ Sin embargo, esa no hubiese sido la tragedia principal. Alvarado expone una posibilidad más peligrosa aún:

Alfonso Reyes cargó toda su vida el luto por la muerte de su padre y ese luto se advierte en la parte más importante de su obra, constituye el aliento de sus mejores páginas y el aceite de su lámpara. Mas, ¿cómo hubiera sido el Alfonso Reyes, errante por el mundo y oculto en un rincón, con el apellido de un usurpador? No habría escrito, de fijo, la Ifigenia cruel y el soplo ateniense, acaso le hubiera servido para un patético y quizá mudo acto de constricción. Otra habría sido la obra de Alfonso Reyes, otra la escena de la cultura mexicana y quizá fuera bueno decidir si, a pesar de todo, no fue mejor lo sucedido (1985: 53).

La muerte de padre fue la confirmación del hijo como escritor. El tránsito más difícil hacia la definición de sujeto: un sujeto cruzado por la pérdida, por la urgencia de recurrir al mundo de la ficción para completar su propio universo.

Esos territorios de la especulación, donde los verbos se conjugan en subjuntivo, pertenecen al terreno de la dimensión literaria, y el ensayista lo sabía muy bien. La pérdida física del progenitor es irreparable; la construcción discursiva de la figura paterna si es posible. Al recrear al padre Reyes se completaba a sí mismo como sujeto: "Mis hábitos de imaginación vinieron en mi auxilio", confiesa, como vimos más arriba, al hablar de los procesos particulares de su duelo. Por medio de la imaginación creadora, el padre se convirtió en interlocutor del hijo: "Aprendí a preguntarle y a recibir sus respuestas. A consultarle todo. Poco a poco, tímidamente, lo enseñé a aceptar mis objeciones [...]" (1990: 27) Compenetración a través de la evocación. Parte de esto proceso tenía que ver

${ }^{6}$ Para una lectura, desde la perspectiva militar de los acontecimientos de la "Decena Trágica", recomiendo el estupendo ensayo de Adolfo Gilly: Cada quien morirá por su lado. Una historia militar de la decena trágica (2013). 
con el espacio que representaba el padre. Monterrey se convirtió en la zona segura dentro de una era incierta. Una cápsula fuera del mapa y del calendario.

Porque él, el vástago, estaba en el devenir del tiempo. Él se quedó y tuvo que hacer de la desgracia el parto crucial de su definición como individuo. Apenas abatido el general surgió la disyuntiva: ¿qué hacer? ¿Ser la proyección del padre o ser él mismo? La decisión, como sabemos, fue radical: "Lo ignoré todo, huí de los que se decían testigos presenciales, e impuse silencio a los que querían pronunciar delante de mí el nombre del que hizo fuego" (1990: 29). De manera literal, se arrancó de sí la sed de venganza y ambición.

Irse, dejar atrás el presente incierto y el país ensangrentado: ambos quedarían para él clausurados por mucho tiempo. Alfonso Reyes se exilió, se marchó físicamente de México; pero regresó, de manera literaria, a la casa familiar en Monterrey. Desde los días de estudiante en la ciudad de México, había comenzado la elaboración de esta simbólica zona de resguardo. En los momentos difíciles, de cualquiera índole, se decía: "Consuélate. Acuérdate que, después de todo, allá en Monterrey, te queda algo sólido y definitivo: Tu casa, tu familia, tu padre" (1990: 26). Y, como él mismo confesó más adelante, no eran, en sí, ni el espacio real ni la persona física del padre quienes provocaban su calma, sino la elaboración imaginaria que hacía de ambos. El dolor ante la pérdida tenía más que ver, en sus palabras, con el cruel designio de la fortuna histórica. "No lloro por la falta de su compañía terrestre, porque yo me la he sustituido con un sortilegio o si preferís, con un milagro. Lloro por la injusticia con que se anuló a sí propia aquella noble vida; sufro porque presiento, al considerar la historia de mi padre, una oscura equivocación en la relojería moral de nuestro mundo [...]" (1990: 30). 
Para contrarrestar ese tenebroso decreto del destino, Reyes elaboró su oración y recurrió por igual a los vastos campos de la historia como a los inciertos terrenos de la literatura. Hizo del duelo una forma de creación (y de reflexión). El punto de cruce entre estos dos espacios fue la biografía, la vida, narrada por el hijobiógrafo, del padre. Un relato que iba de lo biológico a lo político, de lo corporal a lo ideológico. Por medio del recuerdo del cuerpo, de las heridas que sufrió a lo largo de su carrera militar, de las sucesivas firmas que tuvo que elaborar, a través, digo, de todos estos elementos, en apariencia nimios, el hijo regresaba, volvía a ingresar, como solía hacerlo en las vacaciones escolares, en el ámbito de la biblioteca paterna. Sus ojos se asombraban ahora (era la mirada de un adulto, de alguien que ahora podría ser contemporáneo del padre) de los títulos y las lecturas que éstos sugerían: Espronceda, Heredia, Othón (de quien era amigo), la Historia de la humanidad, de Cesare Cantú, y ¡los Cantos de vida y esperanza! de Darío: el general leía a Darío: un autor consagrado por su propia generación y el modelo más emblemático de la modernidad literaria hispanoamericana. Entrar a la biblioteca significaba dejar afuera, por un instante, la contingencia histórica. Alfonso Reyes no deseaba caer en la simple apología y resaltar la labor material del otrora gobernador del estado de Nuevo León, aunque de paso señalaba que eso "Todos lo saben, y los que lo niegan saben que se engańan" (1990: 33).

No deseaba tampoco hablar de lo evidente: que la historia oficial, a través de los malos oficios de la politiquería, se había empeñado en silenciar este capítulo de la vida moderna mexicana, aunque toda la Oración se dirige en ese camino. Pero por ahora eso no era lo importante. No. Para él, la casa y la biblioteca, con sus inquilinos, pertenecían ya a otro universo. Y es ese personaje entrañable, el que se ha formado en la lectura de los clásicos hispanoamericanos del siglo XIX y en los libros consagrados de la historia 
universal, el que vemos caer de nueva cuenta, esta vez gracias a la pluma del hijo, víctima de un destino caprichoso y no desprovisto de tintes de tragedia clásica. La narración de la rendición del general en Linares y la descripción de los últimos momentos de su vida son un magno esfuerzo por corregir y humanizar la historia oficial del México moderno. El viacrucis de un político de otro tiempo. ${ }^{7}$

Reyes finalizó la Oración evocando una elocuente imagen tomada de los Cuadros de viaje, de Henrich Heine: la espiga solitaria que ha escapado a la acción aniquiladora del segador. El cuerpo fue segado por la desquiciante circunstancia política, pero en el rostro sin vida del general quedó, como esa espiga rebelde, una sonrisa: Reyes la recogió y con ella construyó la imagen del progenitor que perdurará a través de su escritura. El punto final de este duelo escritural conmemora la fecha de nacimiento del progenitor: el texto es también una forma de parto. Podríamos, de hecho, verlo así: la Oración del 9 de febrero como una corrección a la historia oficial, el capítulo que faltaba a la gestación del México actual; también mirarla de este otro modo: la Oración como un texto heterodoxo de la narrativa sobre la Revolución Mexicana. En las dos lecturas el proceso es similar: contrarrestar con el factor trascendental de lo local, de lo personal, el peso y el artificio de la nacional u oficial.

${ }^{7}$ Incluso el testimonio de su hermano Rodolfo, cómplice, como ya apunté, de la última empresa militar del general, así lo confirma. Bernardo Reyes sabía, al dirigirse al Palacio Nacional esa mañana de domingo 9 de febrero de 1913, que iba a morir y deseaba morirse a su manera, por cuenta propia: ser consecuente con su propia visión de la historia y de la patria. Confiesa el hermano, recordando esos momentos en los que adelantaba su caballo para alcanzar al padre y disuadirlo de su alocada obsesión: "Para mí, mi padre estaba resuelto a morir en caso de fracaso, y al medir la situación pensó que, de no imponerse con su sola presencia, ese fracaso era seguro, y él, me lo dijo cien veces, no le quería sobrevivir. Su acción no fue, pues, un impulso ciego, sino una resolución suprema. Cuando contestó a mi última palabra, comprendía ya que hacían fuego, y aceptó el sacrificio; lo buscó como la única solución para su propia personalidad" (1929: 240). 
Es un escrito de naturaleza herética que contradice la verticalidad de la cultura oficial mexicana, y a su manera afirma que no hay una sola manera de ser mexicano, o de ser escritor. Confirma igualmente que la memoria debe formar parte de la historia, y que la ficción es parte de la biografía y de la autobiografía.

La Oración del 9 de febrero es, junto con la "Respuesta a sor Filotea de la Cruz", de Sor Juana Inés de la Cruz y las Memorias, de fray Servando Teresa de Mier, una obra de índole única en la literatura mexicana: un sol negro con su propia órbita. Su genealogía proviene de Jorge Manrique (tal vez más allá, desde el Cid), pero también parte de Kafka y se proyecta en Jaime Sabines y en Philip Roth. Es una tradición marcada por el anhelo que alguna vez expresó Elías Canetti: escribir para vencer a la muerte, es también una batalla pérdida. Por eso se lleva a cabo con todos los sentidos.

La escritura ha hecho las veces de duelo. Aceptar la muerte del padre, ha implicado para él aceptar su propia mortalidad. Reyes comenzó su Oración del 9 de febrero implorando el significado trascendental de un fecha y la terminó recitando mentalmente esta frase de Heine para sobreponerse al irremediable arribo de la partida definitiva: "Pero al fin llegará el día, y se extinguirá el fuego en mis venas, el invierno habitará en mi pecho, sus blancos copos revolotearan acá y allá en torno a mi cabellera, y sus nieblas velarán mis ojos. Descansarán mis amigos en sus tumbas, ya cubiertas de verdura; yo solo sobreviviré como espiga solitaria olvidada por el segador [...]" (2003: 211). 


\section{Bibliografía}

Alvarado, José, 1985, Visiones mexicanas, México, SEP (Lecturas mexicanas 68.

Barrera Enderle, Víctor, 2006, De la amistad literaria (Ensayo sobre la genealogía de una amistad: Alfonso Reyes / Pedro Henriquez Ureña, 1906-1914), Monterrey, UANL.

Freud, Sigmund, 2006, "Duelo y melancolía", en Obras completas, vol. XIV, James Strachey (ordenamiento, comentarios y notas), José L. Etcheverry (trad.), Buenos Aires, Amorrortu.

Gilly, Adolfo, 2013, Cada quien morirá por su lado. Una historia militar de la decena trágica, México, ERA.

Heine, Heinrich, 2003, Cuadros de viaje, Isabel García Adánez (intro., trad., y notas), Madrid, Gredos.

Reyes, Alfonso, 2010, Diario, vol. II, 1927-1930, Adolfo Castañón (ed. crítica, intro., notas, fichas biobibliográficas e índice), México, FCE.

, 1990, Oración del 9 de febrero, en Obras completas, vol. XXIV, México, FCE.

Reyes, Rodolfo, 1929, De mi vida. Memorias politicas, tomo I, 1899-1913, Madrid, Biblioteca Nueva.

(Recibido: 18 de enero de 2015, aceptado: 14 de abril de 2015) 